\title{
A virada da arte pública e a formação do artista contemporâneo
}

\author{
The Turn of Public Art \\ and the Education of the Contemporary Artist
}

\author{
El giro del arte público \\ y la formación del artista contemporáneo
}

Luiz Sérgio de Oliveira *

http://dx.doi.org/10.22409/poiesis. 2033.237-256

\begin{abstract}
RESUMO: A arte contemporânea não tem se esquivado em eleger e utilizar os espaços públicos para sua inscrição no mundo mundano e para com ele estabelecer processos de diálogos e de interação que transformam radicalmente a natureza da arte. Neste processo, a arte contemporânea avança em territórios anteriormente reservados e consagrados para a arte pública, em um fenômeno que carreia uma série de implicações e de questões, entre as quais pretendemos enfrentar neste artigo aquela que trata da educação do artista, em um processo de formação que o habilite a enfrentar essa nova realidade da arte.
\end{abstract}

PALAVRAS-CHAVE: arte contemporânea; arte pública; formação do artista

\footnotetext{
* Luiz Sérgio de Oliveira é artista e professor titular do Departamento de Arte da Universidade Federal Fluminense. É doutor em Artes Visuais (História e Teoria da Arte) pela UFRJ, com estágio de doutorado junto à Universidade de San Diego (USD), Estados Unidos, e mestre em Arte pela Universidade de Nova York (NYU), Estados Unidos. É pesquisador integrante do Grupo de Estudos sobre Arte Pública no Brasil (GEAP-BR), vinculado ao GEAP Latinoamérica. E-mail: luizsergiodeoliveira.br@gmail.com; Orcid: https://orcid.org/0000-0002-8616-5089
} 
ABSTRACT: Contemporary art has not shied away choosing and using public spaces for its inscription in the mundane world, in order to establish processes of dialogue and interaction that radically transform the nature of art. In this process, contemporary art advances in territories previously reserved and consecrated for public art, in a phenomenon that carries a series of implications and questions, among which we intend to confront in this article the one that deals with the education of the artist, in a process that enables him to face this new reality of art.

KEYWORDS: contemporary art; public art; education of the artist

RESUMEN: El arte contemporáneo no se ha esquivado en elegir y utilizar los espacios públicos para su inscripción en el mundo mundano, para con él establecer procesos de diálogos y de interacción que transforman radicalmente la naturaleza del arte. En este proceso, el arte contemporáneo avanza en territorios anteriormente reservados y consagrados para el arte público, en un fenómeno que lleva una serie de implicaciones y de cuestiones, entre las cuales pretendemos enfrentar en este artículo aquella que trata de la educación del artista, en un proceso de formación que le permita enfrentar esta nueva realidad del arte.

PALABRAS CLAVE: arte contemporáneo; arte público; formación del artista

Como citar: OLIVEIRA, Luiz Sérgio de. A virada da arte pública e a formação do artista contemporâneo. Poiésis, Niterói, v. 20, n. 33, p. 237-256, jan./jun. 2019.

doi: http://dx.doi.org/10.22409/poiesis.2033.237-256

Poiésis, Niterói, v. 20, n. 33, jan./jun. 2019. 


\section{A virada da arte pública e a formação do artista contemporâneo}

\section{Arte e o mundo mundano}

No contemporâneo, instaurou-se certa convergência entre os artistas de que o lugar culturalmente e politicamente adequado para a emergência da arte são os espaços públicos. Isso parece de imediato gerar um conflito, já que esse novo lugar de inscrição da arte contemporânea - os espaços públicos das cidades - permanecia antes reservado para a arte pública, constituindo-se como algo que a caracterizava e a distinguia. Neste sentido, a arte contemporânea não se esquiva em eleger e utilizar os espaços públicos para inscrever-se no mundo mundano, para com ele estabelecer processos de diálogos e de interação que transformam radicalmente a natureza da arte, o que pode ser entendido como o ápice, mas também como o crepúsculo de uma noção de arte pública. 
Diante desta constatação, algumas questões se impõem e demandam nosso escrutínio: como proceder a educação do artista de maneira que seja possível enfrentar esta nova realidade da arte? Que conhecimentos, habilidades e saberes precisam ser estimulados nesse processo de educação do artista contemporâneo comprometido com inserções de arte no mundo mundano? Não é difícil concluir que, mesmo em cursos de arte que se organizam em torno de perspectivas diferentes daquelas ressaltadas nas escolas de belas artes, parece haver a predominância de um processo de formação nuclearizada e focada na figura do artista, em uma (re)afirmação exponencial de sua centralidade e na exacerbação de sua individualidade, como se a arte estivesse no artista, sendo nele residente permanente. No entanto, uma arte que se articula em processos de interação com o mundo demanda uma formação diferenciada, baseada na escuta e no diálogo, e não simplesmente na replicação e na reafirmação de monólogos que, por séculos, caracterizaram a presença do artista na vida social.

\section{Arte contemporânea como arte pública}

Se a definição de arte pública sempre se deu sob a égide do conflito e de debates circulares, como aqueles que sugerem que inevitavelmente toda arte é pública, o que poderia ser dito nos dias atuais quando a arte contemporânea se espalha com desenvoltura pelos espaços públicos? O que poderia ainda significar a denominação arte pública no cenário contemporâneo da arte? Para além dos processos celebratórios que inundaram jardins e praças das cidades com monumentos em exaltação a processos coloniais de nossa história oficial, há algumas poucas décadas talvez esses conflitos encontrassem alguma conciliação e um ponto de convergência na compreensão de que a arte pública incorporaria outras manifestações de arte, além da grande escultura em bronze, e que o processo de expansão da arte pública fazia-se sob a chancela da desmaterialização experimentada no lastro do conceitualismo dos anos 1960. Caminhando no sentido da superação da escultura tradicional, a arte pública dos anos 1990 apontava a necessidade de ocupação dos espaços em processos de diálogo e de interação com aqueles que ocupam esses espaços,

Poiésis, Niterói, v. 20, n. 33, jan./jun. 2019. 
algo que a artista Suzanne Lacy preferiu nomear como "novo gênero de arte pública". ${ }^{1}$ Para a também artista Judith Baca, os usos e aplicações do termo arte pública "em uma audiência de muitas culturas traz diferentes imagens à mente de cada um de nós. Talvez alguns imaginem os afrescos e as estátuas da Renascença italiana ou os guarda-chuvas de Christo, enquanto outros veem os murais de Los Tres Grandes ou o ritual das pinturas de areia e totens dos povos nativos" (BACA, 1995, p. 131), ao que poderíamos acrescentar uma infinidade de manifestações que transitam entre o sagrado e o profano no rico universo cultural brasileiro.

De qualquer maneira, os estudos em torno da arte pública revelam que as práticas oficiais de ocupação dos espaços públicos com manifestações de arte de cunho celebratório são inadequadas tanto pela perspectiva da arte quanto pela construção de uma narrativa histórica que represente minimamente os interesses da coletividade. Essa arte celebratória não consegue ultrapassar o estreito caminho de uma visão unilateral da história. São manifestações típicas de uma "arte pública a serviço da dominação. Por sua presença diária em nossas vidas, essas obras tentam persuadir-nos da justiça dos atos que representam". (BACA, 1995, p. 132)

Por outro lado, se a arte avança em direção a outras possibilidades de ocupação do espaço público, eventualmente desmaterializada em ações de cunho performativo ${ }^{2}$ que se esmeram em potencializar as possibilidades da arte em sua caminhada/expansão no mundo mundano, outras questões e outras surpresas se impõem, representadas por aqueles que, distanciados do mundo da arte, têm a oferecer ao artista um material social e humano que pode (e)levar a produção do artista a outros patamares, ou melhor dizendo, ajudando-o a manter sua produção no lugar ao qual pertence, ao rés do chão do mundo que é especial exatamente por ser mundano. A curadora Mary Jane Jacob enfatiza que quando o artista deixa seu reduto tradicional e se esgueira pelas capilaridades das cidades e do tecido social, se percebe um fenômeno no qual "o público [cativo da arte] não expandiu, mas foi substituído. Na verdade, é essa mudança na composição do público, e sua posição no centro criativo, que torna esta arte pública tão nova". (JACOB, 1996, p. 59) 
A historiadora e crítica Harriet F. Senie destaca ainda que "a arte pública opera fora do sistema de galerias; ela não pode ser exibida em museus, exceto sua documentação (desenhos, modelos, fotografias). E, mais significativamente, sua função econômica não gera receitas dentro do circuito comercial de arte. Se for encomendada diretamente ao artista, pode não haver comissão para a galeria". (SENIE, 2003, p. 45) É necessário, portanto, reconhecer que o deslocamento da produção de arte contemporânea em direção aos espaços públicos é um fenômeno que não é nem nunca foi apoiado pelo circuito comercial, o chamado mainstream, integrado por galerias, museus, feiras de arte, publicações comerciais, além de uma crítica de arte comprometida com este circuito, por ser uma produção sobre a qual o circuito não exerce qualquer controle. Um fenômeno que no início dos anos 1990 foi identificado como sendo próprio de uma "nova arte pública" (JACOB, 1996), "arte pública crítica" (MITCHELL, 1990) ou "novo gênero de arte pública" (LACY, 1996), e que nos dias atuais é simplesmente arte contemporânea.

Para além deste debate em torno das premissas e territorialidades da arte pública, a produção de arte contemporânea tem privilegiado os espaços públicos como o lugar da arte. Muito da arte contemporânea é dependente das relações que se estabelecem em seu espalhamento para além dos espaços tradicionalmente reservados para a emergência da arte - museus, galerias de arte, centros culturais etc. É neste novo lugar da arte que esta produção contemporânea faz emergir processos de encontros que são constitutivos de sua natureza. Portanto, esses encontros e diálogos estabelecidos no próprio processo de criação/participação/consumo da arte em situações/contextos que são criados ou reinventados pelas práticas de arte são a nova natureza de uma arte que se fez e que se quer dialógica, interativa e participativa.

Assim, as práticas de arte de caráter efêmero que transbordam e assumem os espaços públicos como seus acentuam os processos e o "fluxo a ser experimentado no próprio processo de criação, algo que tem a duração de um sopro, o sopro da criação, e que se apresenta para quem está presente no momento da criação, no momento presente da instauração da arte no processo criativo". (OLIVEIRA, 2015, p. 109)

Poiésis, Niterói, v. 20, n. 33, jan./jun. 2019. 
Este deslocamento, portanto, é essencialmente um movimento de artistas na tentativa de alcançar uma nova inscrição social para sua produção de arte, algo que se dá à revelia do mainstream, que, no entanto, permanece sempre atento e ativo na seleção de artistas que possam ser escolhidos, "higienizados" e lançados em um circuito que é permanentemente carente de novidades e de processos de revigoramento.

Assim, parece existir certa tendência entre os produtores de arte na identificação dos espaços públicos como o lugar culturalmente e politicamente adequado para a nova inscrição da arte, algo que borra os limites de definição da arte pública, já que se o lugar de inscrição da arte contemporânea são os espaços públicos das cidades, quais seriam então os elementos definidores da arte pública (hoje)? Como já dito, poderia isso representar o colapso de uma ideia de arte pública em favor do reconhecimento de que parte significativa da arte contemporânea é essencialmente pública? Representaria isso o apagamento de uma categoria que vinha sendo identificada como "arte pública", já que é da natureza da arte no contemporâneo estar atrelada à sua condição pública?

Os processos de criação do artista contemporâneo se constituem justamente em torno do desejo de interação com outros, sejam eles/as quem forem, alavancando a ambição da arte de ser (ou de se fazer pública) através do enfrentamento de questões que residem no cotidiano do mundo mundano, questões que são deste mundo e que o constituem. Neste sentido, a produção de arte contemporânea se lança por inteiro em um território antes assumido como próprio da arte pública, torneando um fenômeno que pode ser entendido a um só tempo como o triunfo final e como o crepúsculo de uma noção de arte pública.

\section{A educação do artista contemporâneo}

Os processos de formação do artista tendem a se basear e assim consolidar o mito da autossuficiência da arte e do/a artista, o que nos conduz à inabalável percepção de que a educação do artista deve ter no próprio artista mais do que seu eixo central, mas o eixo 
único em torno do qual supostamente o mundo giraria. É por esta razão que as escolas de arte, particularmente as de belas artes, centram suas metodologias de ensino e de educação do artista nos estudos técnicos dos meios artísticos - desenho de observação, modelo vivo, estudos da forma e da cor, técnicas e materiais de pintura, de gravura, de escultura etc. -, tendo sempre como objetivo e foco prover esse artista em formação com as "ferramentas" necessárias para que ele tenha condições de revelar ao mundo suas verdades, aquilo que ele - o artista - tem a dizer deste mundo ou de outros mundos, sempre através de discursos monológicos. Essas práticas de formação parecem comprometidas com a ideia de que "esse ter algo a dizer para o mundo", território dos monólogos do artista, sempre teve o mesmo lugar como origem - o universo fechado e autossuficiente do artista - e no qual deverá permanecer até que o artista, já instrumentalizado, possa oferecer "esse algo a dizer" ao mundo.

Mesmo nos cursos e escolas de arte que procuram alternativas àquela formação do artista centrada no domínio das técnicas, dos materiais e dos meios tradicionais das belas artes, mesmo esses cursos parecem ratificar um processo de educação do artista em convergência exagerada na figura desse artista, em um processo de (re)afirmação exponencial de sua individualidade. Dessa maneira, reforçam-se teorias e mitos que se replicam indefinidamente, como se em uma sala totalmente espelhada, de que a arte está no artista, sendo nele residente permanente. Esses cursos, independentemente de suas intenções, objetivos e metodologias, não evitam as confluências de forças e de assunções que tornam o artista um prisioneiro-de-si-mesmo-e-de-suas-verdades.

Esses cursos e escolas de arte não conseguem se desvencilhar das armadilhas em que a arte se viu encerrada: de que o processo de arte depende unicamente e exclusivamente do artista, e de nada mais que esteja além de sua força criativa alimentada por uma sensibilidade única. Uma arte cujo florescimento depende somente dele - o artista -e em torno dele se constitui, colocando o mundo sempre em uma espera passiva dos movimentos, atitudes, gestos e criações singulares do artista. Mas a arte não é isso, não é somente isso nem necessariamente isso.

Poiésis, Niterói, v. 20, n. 33, jan./jun. 2019. 
As convergências em processos de formação indiscriminadamente centrados no artista aproximam cursos que se apresentam como mais avançados ou experimentais daqueles comprometidos com os cânones das belas artes. Apesar das diferenças de metodologias e das compreensões distintas acerca da natureza da arte contemporânea, esses tipos divergentes de educação do artista depositam indistintamente suas expectativas nos atributos e nas singularidades do artista, como se fossem absolutamente imprescindíveis e inteiramente suficientes para a emergência de uma arte capaz de encantar o mundo. Os tratados da história e da sociologia da arte têm ajudado a viralizar mitos criados em torno da personalidade do artista, algo que encontra nas investigações da vida/obra de grandes mestres do passado, como Vincent Van Gogh, "a sua mais completa tradução".

Independentemente dos tipos de curso e de educação, tendemos sempre a construir cenários de isolamento do artista e da arte nas sociedades contemporâneas, como se a arte se inscrevesse em um território próprio e autônomo (e ali devesse permanecer), como se a autonomia da arte fosse ontologicamente parte de sua natureza, como se às coisas do mundo mundano bastasse tangenciar, na distância, o mundo da arte, e vice versa.

É verdade que este cenário tem mudado; não se pode dizer que a produção de arte tenha atravessado incólume as sucessivas tentativas das vanguardas históricas do início do século $X X$, das neovanguardas ${ }^{3}$ e das geovanguardas ${ }^{4}$ em passados mais recentes. No entanto, permanecem muitas dúvidas de quanto essas mudanças na dinâmica e na natureza da arte têm afetado a educação do artista e as arquiteturas curriculares das escolas de arte. Ou, invertendo nossa perspectiva, como as escolas, faculdades e institutos de arte têm respondido a uma nova realidade que catapulta a arte em direção ao mundo mundano: é possível detectar algum redirecionamento no processo de educação do artista? Alguma nova orientação tem iluminado os currículos dos cursos de arte? Que disciplinas e áreas de conhecimento têm sido introduzidas para ajudar o artista em formação, para ajudar esse artista para que consistentemente se situe no mundo? 


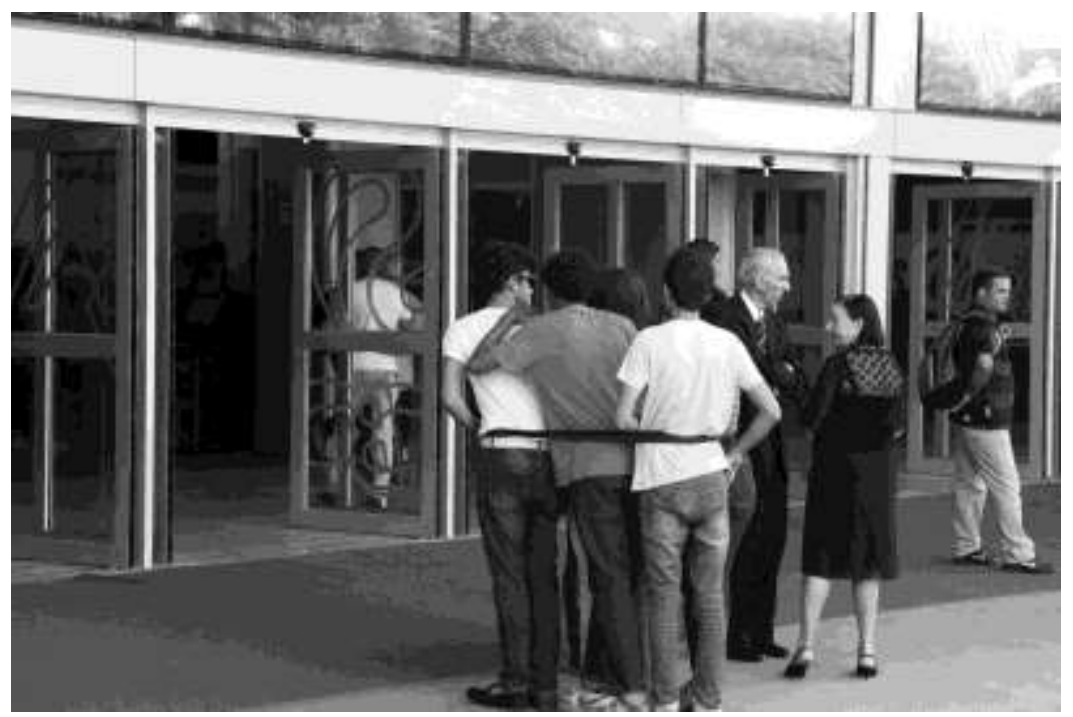

Fig. 1 - Transporte Coletivo, 2014. ação urbana.

(Praça Araribóia, Niterói)

Poiésis, Niterói, v. 20, n. 33, jan./jun. 2019. 


\section{Transporte coletivo: os tropeços de uma caminhada}

Uma experiência desenvolvida no âmbito do curso de graduação em Artes da Universidade Federal Fluminense, Niterói, em 2014, pode se configurar como uma oportunidade para refletirmos acerca da educação do artista a partir de questionamentos introduzidos por práticas da arte contemporânea que elegem o espaço público como lugar de sua emergência. A experiência em questão envolveu estudantes do primeiro período do curso, estudantes recém ingressados na universidade ${ }^{5}$, que foram confrontados, já na chegada, por uma série de indagações e de debates que buscava desconstruir assunções consolidadas a respeito da arte e da percepção do lugar do artista no mundo.

Esses debates pareciam exercer certa atração e poder de sedução sobre alguns estudantes, não exatamente sobre todos, uma vez que alguns pareciam ter dificuldades em abandonar uma postura de passividade e de menor participação, em parte decorrente de experiências educacionais anteriores, ou mesmo de sua juventude. No entanto, deve-se reconhecer o valor de cada e de todas as experiências - independentemente do estágio de cada um na vida, de sua percepção do mundo e das coisas do mundo -, entendendo que todas as experiências merecem a condição de partilha e podem/devem enriquecer o debate da arte, da vida e do viver. Essas dificuldades não impediam que questões fossem lançadas e provocassem o pensamento crítico-criativo em torno de mitos que compõem o imaginário social do artista e que, de uma maneira ou de outra, acabam por impactar a educação do artista.

Uma oportunidade de maior participação se deu quando uma pilha de câmaras de ar de pneus de bicicletas foi trazida para a sala com o intuito de provocar a criatividade dos estudantes a partir do uso de um material um tanto incomum, se é que essa afirmação ainda carreia algum sentido no fazer artístico contemporâneo. A partir desse material, deixado no piso da sala como se fosse um ninho de cobras pretas, algumas propostas começaram a se multiplicar com a rapidez do processo criativo de jovens artistas em formação. Em um processo natural de seleção, as propostas foram sendo abandonadas em suces- 
são, enquanto algumas permaneciam e conseguiam manter o interesse dos estudantes/jovens artistas envolvidos.

Alguns poucos encontros após o primeiro surgimento do "ninho de cobras" no canto da sala, uma proposta parecia ter angariado a confiança dos estudantes, que cuidaram de discuti-la e aperfeiçoá-la: Transporte Coletivo. Das inúmeras câmaras de ar de bicicleta que haviam chegado, uma foi destacada e seria usada para conter o maior número possível de pessoas em sua quase-circunferência. Depois de alguns testes, o número cinco firmou-se como o máximo que a câmara de ar comportaria - no caso, cinco estudantes que, assim comprimidos em um espaço bem inferior a $1 \mathrm{~m}^{2}$, iriam usar a câmara como veículo para seu deslocamento em uma ação no espaço público.

O passo seguinte foi o de estabelecer o percurso para a ação: definiu-se que o Transporte Coletivo se deslocaria do campus da Universidade Federal Fluminense, no Gragoatá, Niterói, em direção ao Museu de Arte do Rio (MAR), na Praça Mauá, cidade do Rio de Janeiro, instituição que, à época, acolhia atividade do curso de graduação em Artes da UFF. O percurso incluiria duas longas caminhadas - a primeira, do Gragoatá à estação das barcas no Centro de Niterói, e a segunda no Centro do Rio, da Praça XV à Praça Mauá -, além da travessia marítima da baía de Guanabara. A ação consumiu um tempo extremamente alongado em função das dificuldades enfrentadas no percurso, quando alguns estudantes foram literalmente arrastados pelos colegas como consequência da exiguidade do espaço partilhado.

Como era possível prever, a passagem do grupo, exprimido em uma câmara de ar, pelas ruas das duas cidades - Niterói e Rio de Janeiro - provocou descontinuidades, conforme conceito utilizado por José Luiz Kinceler para designar situações nas quais "alterações se processam na forma como o sujeito compreende a si mesmo neste mundo" ${ }^{6}$. Neste sentido, a passagem inusitada do Transporte Coletivo pelas ruas das duas cidades fez com que passantes interrompessem os fluxos de seus percursos para, com certa perplexidade, tentar entender o que (se)passava diante de seus olhos. Neste sentido, Transporte Coletivo promoveu a suspensão da continuidade dos processos mentais desses habitantes da cida-

Poiésis, Niterói, v. 20, n. 33, jan./jun. 2019. 
de, com diria Michel de Certeau, que, por sua vez, se deixavam impactar por uma experiência de arte provocada por algo singular e extraordinário em seu cotidiano.

Da mesma maneira, a chegada ao Museu de Arte do Rio, lugar destinado ao acolhimento de experiências da arte, também gerou ruídos no âmbito institucional, quando o grupo de cinco estudantes do Transporte Coletivo se apresentou na recepção da instituição como um só corpo e uma única identidade, ao invés de cinco individualidades.

Transporte Coletivo foi uma experiência realizada em 2014 que ajudou os estudantes envolvidos a alcançar uma melhor compreensão de questões que se avultam no cenário contemporâneo da arte. Questões que empurram os artistas e os estudantes de arte a se lançarem em situações que compõem o cotidiano das grandes cidades e daqueles que nelas habitam, e que primam por retirar o artista de seu isolamento em favor de uma inserção mais ativa no tecido social. Isso não implica aceitar que a arte e o artista têm uma capacidade substantiva para enfrentar os graves problemas sociais que incidem sobre o mundo mundano. Não é disso que aqui e nas aulas em questão tratamos. Entretanto, o que se pretende é que o artista seja e se sinta parte do mundo, que neste mundo atue, independentemente das mazelas do mundo. E que possa, de dentro deste mundo imperfeito, imaginar e fazer sonhar por algo melhor.

Nestas práticas que temos desenvolvido junto aos estudantes ingressantes do curso de graduação em Artes da UFF, alguns pontos de relevância merecem ser assinalados, como aquele que se relaciona às práticas de arte contemporânea de caráter colaborativo que elegem os espaços públicos como lócus para sua instauração: Transporte Coletivo potencializou a diluição da autoria pelo conjunto de estudantes /artistas que abraçaram o projeto desde sua emergência, de maneira que tornou impossível identificar ou destacar autor(es) ao longo de seu processo de criação, de sua elaboração e de sua realização. Além disso, seu aspecto performativo impediu que a ação fosse apropriada em outras instâncias ou em outros ambientes, tendo sido realizada nas ruas das cidades de Niterói e do Rio de Janeiro e desaparecido sem deixar outros vestígios que não algumas imagens a cumprir o papel da documentação.

Poiésis, Niterói, v. 20, n. 33, jan./jun. 2019. 


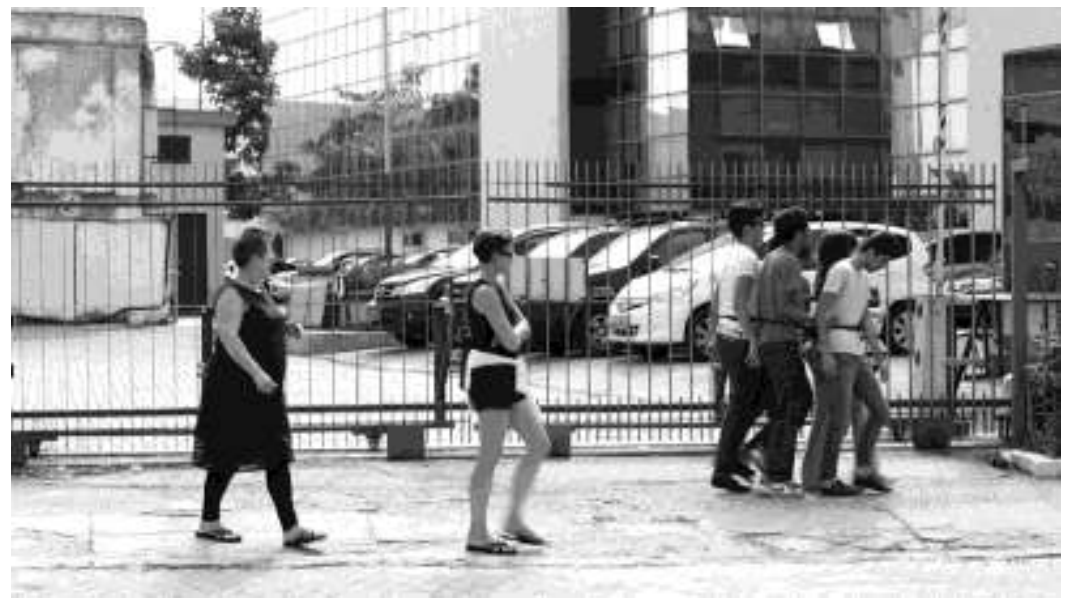

Fig. 2 - Transporte Coletivo, 2014. ação urbana. (São Domingos, Niterói)

Poiésis, Niterói, v. 20, n. 33, jan./jun. 2019. 


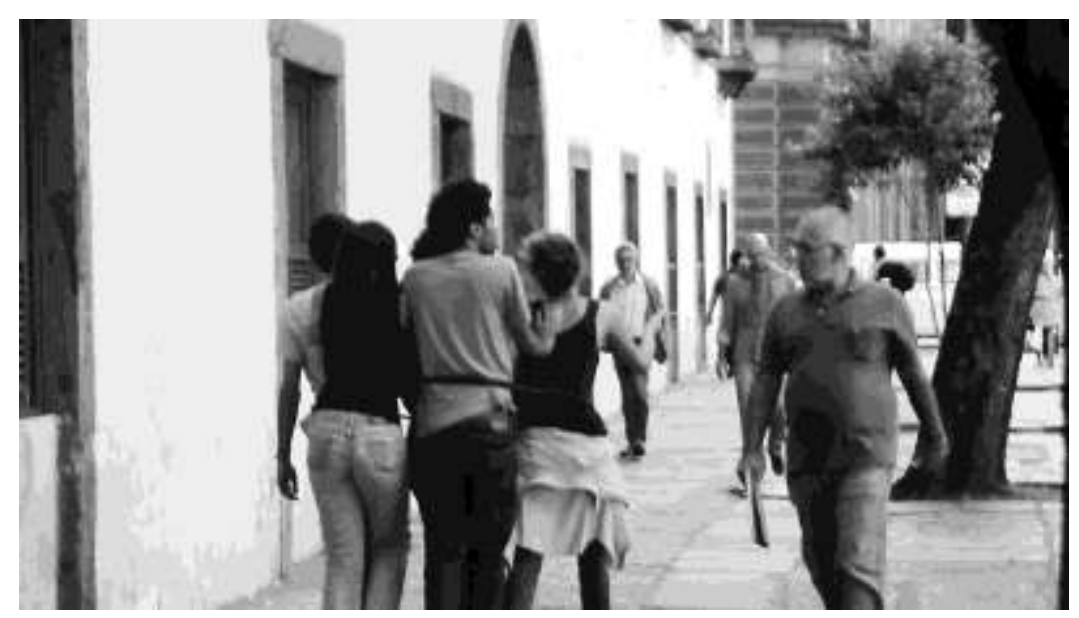

Fig. 3 - Transporte Coletivo, 2014. ação urbana.

(Avenida Primeiro de Março, Centro, Rio de Janeiro)

Poiésis, Niterói, v. 20, n. 33, jan./jun. 2019. 
Outro ponto a merecer destaque é o fato de que, apesar de bem-sucedido em sua realização e impacto nas ruas das cidades, o projeto Transporte Coletivo não dissolveu nem suprimiu as incertezas que rodeiam o processo de educação do artista no contemporâneo quando estimulam práticas de arte que se afastam das tradições e do interesse do mainstream. As práticas de arte contemporânea nos espaços coletivos, quer tenham caráter colaborativo ou não, com diferentes graus de participação, práticas contemporâneas que, por sua natureza, enfatizam as vinculações políticas da arte com as coisas do mundo mundano, sublinham a necessidade de que o processo de educação do artista seja revisto, repensado e reinventado, enfrentando assunções do universo renitente das belas artes que permanecem acolhidas mesmo nos territórios de formação do artista contemporâneo que se supõe avançada. 


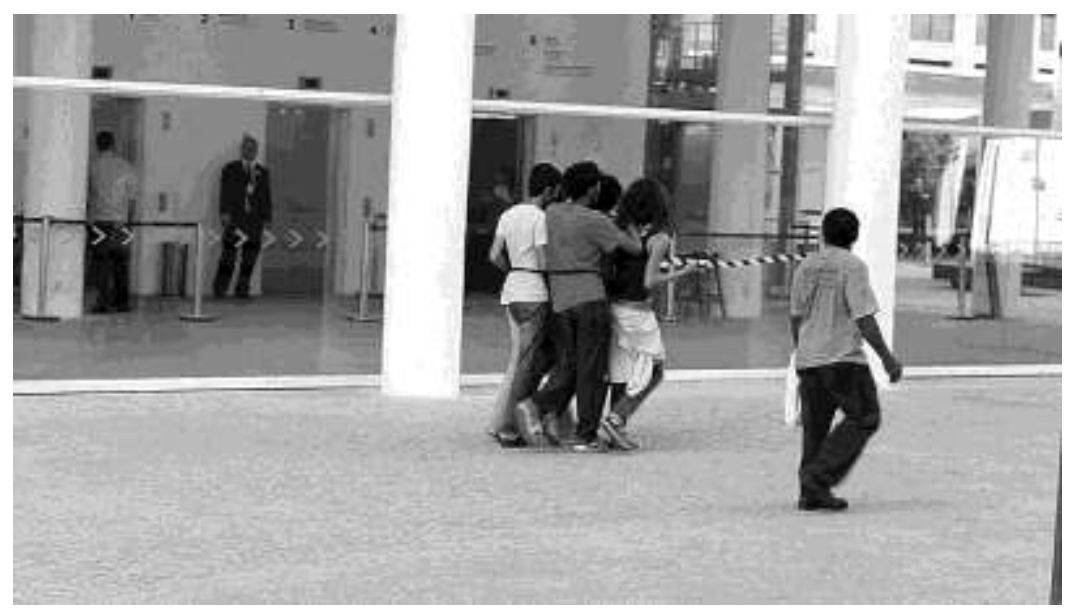

Fig. 4 - Transporte Coletivo, 2014. ação urbana. (Praça Mauá, Rio de Janeiro) 


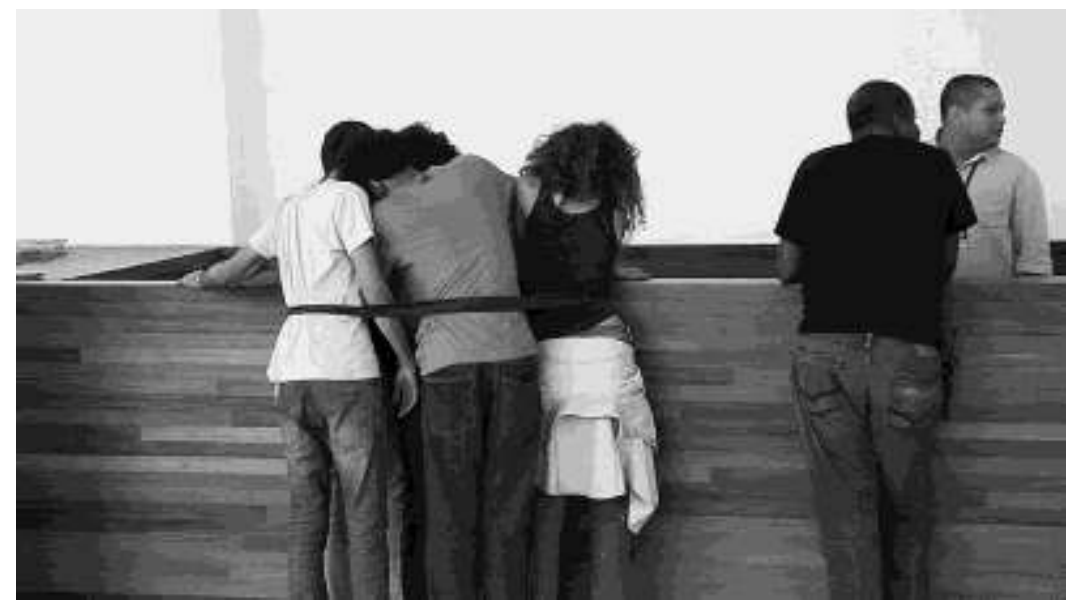

Fig. 5 - Transporte Coletivo, 2014. ação urbana.

(Portaria do Museu de Arte do Rio, Rio de Janeiro)

(As imagens foram cedidas por Daniel Moreira, Filipe Britto, Jaquie de Carvalho,

Ludmylla Tavares, Luiza Magalhães, Maria Rebel e Paula Stephanie Borges)

Poiésis, Niterói, v. 20, n. 33, jan./jun. 2019. 


\section{Notas}

${ }^{1}$ A respeito, consultar LACY, Suzanne (Ed.). Mapping the Terrain - New Genre Public Art. Seattle, Wash.: Bay Press, 1996.

${ }^{2}$ A respeito ver HEARTNEY, Eleanor. The Dematerialization of Public Art. In: Critical Condition: American Culture at the Crossroads. Cambridge: Cambridge University Press, 1997, pp. 206-218.

${ }^{3}$ A respeito, ver o debate desenvolvido entre Hal Foster (The Return of the Real. Cambridge, Mass.: The MIT Press, 1996) e Peter Bürger (Teoria da Vanguarda. Trad. De Ernesto Sampaio. 1. ed. Lisboa: Vega / Universidade, 1993 [1974]).

${ }^{4}$ A respeito, ver OLIVEIRA, Luiz Sérgio de. Vanguardas, neovanguardas, geovanguardas: os desafios metodológicos da história da arte diante das novas práticas de arte na esfera pública. Anais do V Congreso Internacional de Teoría e Historia de las Artes XIII Jornadas CAIA, 2009, Buenos Aires. Balances, perspectivas y renovaciones disciplinares de la historia del arte. Buenos Aires: Centro Argentino de Investigadores de Arte - CAIA, 2009. v. 1. pp. 6777.

${ }^{5} \mathrm{O}$ projeto Transporte Coletivo foi concebido e realizado pelos estudantes listados a seguir: Bárbara Perobelli, Beatriz Cohen, Bruno Torres, Celso Albuquerque, Daniel Moreira, Elisa Junger, Filipe Britto, lagor Peres, Jaquie de Carvalho, Jessica Figueiredo, Julia Vita de Carvalho, Juliane Rodrigues, Kyara Massiere, Leonardo Egito, Letícia Falcão, Lorena Tavares, Lucas Mattos, Ludmylla Tavares (monitora), Luiza Magalhães, Maria Rebel, Nathali Bispo dos Santos, Nathasha Granja, Paula Stephanie Borges e Valeska Galvão.

${ }^{6}$ Ver KINCELER, José Luiz. As noções de descontinuidade, empoderamento e encantamento no processo criativo de "Vinho Saber - arte relacional em sua forma complexa". Anais do $17^{\circ}$ Encontro Nacional da Associação Nacional de Pesquisadores em Artes Plásticas, Florianópolis, 2008, p. 1789-1800. Disponível em http://anpap.org.br/ anais/2008/artigos/162.pdf. 


\section{Referências}

BACA, Judith F. Whose Monument Where? Public Art in a Many-Cultured Society. In LACY, Suzanne (Ed.). Mapping the Terrain: New Genre Public Art. Seattle, Wash.: Bay Press, 1995, pp. 131-138.

BÜRGER, Peter. Teoria da Vanguarda. Trad. De Ernesto Sampaio. 1. ed. Lisboa: Vega / Universidade, 1993 [1974].

FOSTER, Hal. The Return of the Real. Cambridge, Mass.: The MIT Press, 1996.

HEARTNEY, Eleanor. The Dematerialization of Public Art. In Critical Condition: American Culture at the Crossroads. Cambridge: Cambridge University Press, 1997, pp. 206-218.

JACOB, Mary Jane. An Unfashionable Audience. In LACY, Suzanne (Ed.). Mapping the Terrain - New Genre Public Art. Seattle, Wash.: Bay Press, 1996, pp. 50-59.

KINCELER, José Luiz. As noções de descontinuidade, empoderamento e encantamento no processo criativo de "Vinho Saber - arte relacional em sua forma complexa". Anais do $17^{\circ}$

Encontro Nacional da Associação Nacional de Pesquisadores em Artes Plásticas, Florianópolis, 2008, p. 1789-1800. Disponível em http://anpap.org.br/anais/2008/artigos/162.pdf

LACY, Suzanne (Ed.). Mapping the Terrain - New Genre Public Art. Seattle, Wash.: Bay Press, 1996.

MITCHELL, W. J. T. The Violence of Public Art: "Do the Right Thing". Critical Inquiry, v. 16, n. 4, pp. 880-899, verão 1990.

OLIVEIRA, Luiz Sérgio de. O lugar da arte e o desprestígio do objeto artístico. In CIRILLO, José; GRANDO, Angela (Org.). Mediações e enfrentamentos das artes. São Paulo: Intermeios, 2015, pp. 105-116.

OLIVEIRA, Luiz Sérgio de. Vanguardas, neovanguardas, geovanguardas: os desafios metodológicos da história da arte diante das novas práticas de arte na esfera pública. Anais do V Congreso Internacional de Teoría e Historia de las Artes / XIII Jornadas CAIA. Buenos Aires: Centro Argentino de Investigadores de Arte - CAIA, 2009. v. 1. pp. 67-77.

SENIE, Harriet F. Responsible Criticism: Evaluating Public Art. Sculpture, v. 22, n. 10, dez. 2003, pp. 44-49.

Poiésis, Niterói, v. 20, n. 33, jan./jun. 2019. 